\title{
Perancangan Video Musik Naratif untuk Menambah Kesadaran Remaja Tingkat Akhir Mengenai Bahaya Obsessive Love Disorder
}

\author{
Michael Aldi Kurniawan ${ }^{1 *}$, Hendian Yudani², I Gusti Ngurah Wirawan ${ }^{3}$ \\ 1,2 Program Studi Desain Komunikasi Visual, Fakultas Seni dan Desain, \\ Universitas Kristen Petra, Jl. Siwalankerto 121-131, Surabaya \\ ${ }^{3}$ Desain Komunikasi Visual, Fakultas Seni Rupa dan Desain, \\ Institut Seni Indonesia, Jl. Nusa Indah, Denpasar \\ *Penulis korespondensi; Email: michaelaldikoh@gmail.com
}

\begin{abstract}
Abstrak
Obsessive Love Disorder merupakan suatu kondisi di mana seseorang terobsesi dengan orang yang mereka cintai. Mereka merasa harus melindungi bahkan mengendalikan pasangan nya secara obsesif. Yang menjadi permasalahan adalah banyak remaja yang tidak sadar akan adanya hal ini, dan akhirnya terjebak di dalam sebuah hubungan yang tidak sehat karena sikap obsesif tadi. Maka dari itu, dilakukan perancangan video musik naratif untuk menambah kesadaran remaja tingkat akhir mengenai bahaya dari Obsessive Love Disorder. Perancangan menggunakan metode analisis kualitatif dan $5 \mathrm{~W}+1 \mathrm{H}$, diikuti dengan riset pada target audiens dan para ahli. Hasil dari perancangan ini adalah sebuah video musik naratif yang bermanfaat untuk menambah kesadaran remaja tingkat akhir mengenai bahaya dari Obsessive Love Disorder.
\end{abstract}

Kata Kunci: Video Musik Naratif, Obsessive Love Disorder, Remaja.

\begin{abstract}
Obsessive Love Disorder is a condition in which a person is obsessed with the person they love. They feel like they have to protect and even control their partners obsessively. The problem is that many teenagers are not yet aware of this, and end up stuck in an unhealthy relationship because of the obsessive attitude. Therefore, a narrative music video design is done to increase the awareness of late teens about the dangers of Obsessive Love Disorder. The methods used are qualitative analysis and $5 \mathrm{~W}+1 \mathrm{H}$, followed by research performed on the target audience and experts. The result of this design is a narrative music video that is useful to increase the awareness of late teens about the dangers of Obsessive Love Disorder.
\end{abstract}

Keywords: Narrative Music Video, Obsessive Love Disorder, Teens.

\section{Pendahuluan}

Usia remaja tingkat akhir (18-24 tahun) merupakan usia dimana remaja akan menemui banyak perubahan dalam kehidupan, tujuan hidup, dan proses menemukan jati dirinya. Menurut Frangklin (2018), dalam proses perkembangan fase remaja, remaja banyak dipengaruhi oleh faktor sosial, terutama teman sebayanya. Secara umum, pada masa remaja mereka akan melakukan konformitas dengan kelompok-kelompok pertemanannya. Selain hal itu, remaja juga mulai membangun hubungan interpersonal dengan orang-orang di sekitar (Frangklin, 2018).
Namun sayangnya, tidak semua hubungan yang remaja bangun merupakan hubungan sehat. Bahkan menurut catatan Kementerian Pemberdayaan Perempuan dan Anak sepanjang 2019 (melalui platform SIMFONI), kelompok usia remaja 18-24 tahun menempati peringkat ketiga yang paling banyak mengalami kekerasan dalam pacaran (Ashar, 2019). Kekerasan dalam pacaran seringkali disebabkan oleh sikap posesif yang berakar dari pemikiran obsesif remaja kepada pasangannya. Hal ini dikenal juga dengan Obsessive Love Disorder, yaitu termasuk penyakit gangguan mental yang membuat pengidapnya terobsesi dengan satu orang. Penderita akan merasa 
perlu untuk melindungi orang yang dicintai tersebut secara obsesif hingga tampak mengendalikan hidup orang yang dicintai tersebut.

Menurut Cherney (2018), gejala dari Obsessive Love Disorder ini antara lain tidak bisa menerima penolakan dari pasangan sehingga semua keinginan harus dipatuhi, bahkan ketika penderita melihat pasangannya berbicara dengan lawan jenis dapat membuat penderita cemburu tanpa alasan yang jelas. Mengirim pesan dan panggilan telepon berulang-ulang ke orang yang mereka sukai, kesulitan menjalin pertemanan atau mempertahankan kontak dengan anggota keluarga karena terobsesi terhadap satu orang, selalu memantau tindakan pasangan atau orang yang disukai, berusaha mengendalikan kegiatan orang yang disukai (Cherney, 2018).

Melihat seluruh gejala di atas, Obsessive Love Disorder ini merupakan suatu hal yang berbahaya bagi para remaja. Menurut Ahmadi (2013) dalam sebuah penelitian berjudul "Prevalence of Obsessive Love and Its Association with Attachment Styles", Obsessive Love Disorder dapat disebabkan oleh pola asuh pada masa awal kelahiran. Seseorang yang dibesarkan dalam hubungan yang stabil, justru menjadi orang mandiri ketika dewasa dan tidak memiliki kecenderungan obsesif. Mereka bisa menganggap diri sendiri berharga. Sebaliknya, mereka yang dibesarkan pada keluarga dengan kondisi saling tidak percaya akan menjadi orang yang mudah menaruh curiga pada orang lain, termasuk kepada pasangannya. Selain itu, rasa kesepian mendalam juga bisa menjadi penyebab munculnya cinta obsesif. Ketika mereka menemukan kekasih, mereka merasa telah menemukan bagian yang hilang di dirinya. Misalnya, si obsesif tidak dibesarkan dengan perhatian utuh dari kedua orang tuanya, maka saat memiliki pasangan yang perhatian, si obsesif merasa bahwa kerinduan nya sedikit terobati, meski tak sepenuhnya bisa menggantikan perhatian tersebut (Ahmadi, 2013).

Sehubungan dengan permasalahan di atas, solusi dalam perancangan ini adalah menciptakan sebuah video musik naratif untuk meningkatkan kesadaran para remaja akan bahaya Obsessive Love Disorder karena video musik naratif merupakan video musik yang mempunyai alur cerita di dalamnya selayaknya film pendek, sehingga remaja bisa lebih mudah dalam memahami pesan yang ingin disampaikan. Perancangan ini berupa pembuatan video musik naratif untuk meningkatkan kesadaran remaja terkait dengan bahaya Obsessive Love Disorder yang ditujukan kepada remaja tingkat akhir yang berusia 18-24 tahun.

\section{Metode}

\section{Data Primer}

Pengumpulan data secara mendalam melalui observasi dan wawancara kepada narasumber tentang apa yang mereka ketahui dari Obsessive Love Disorder.

\section{Data Sekunder}

Mencari dan mempelajari psikologi manusia secara umum, dan juga mencari berbagai realita yang sering terjadi di dalam hubungan pacaran para remaja guna lebih memahami karakter penderita Obsessive Love Disorder dan juga hubungan tidak sehat pada remaja.

Pengumpulan data dilakukan dengan dengan wawancara mendalam terhadap narasumber mengenai perilaku dan pola pikir penderita Obsessive Love Disorder, juga melakukan riset tentang seberapa paham remaja tentang Obsessive Love Disorder. Untuk mencari konsep cerita, bisa dengan menyesuaikan dengan lagu yang akan dipakai, juga menonton video musik naratif lain guna meningkatkan referensi sinematografi. Metode analisis data menggunakan $5 \mathrm{~W}+1 \mathrm{H}$.

\section{Pembahasan}

Menurut Cherney (2018), Obsessive Love Disorder (OLD), yaitu mengacu pada suatu kondisi dimana seseorang menjadi terobsesi dengan satu orang yang dipikir akan dicintai. Seseorang tersebut mungkin merasa perlu untuk melindungi secara obsesif, atau bahkan mengendalikan seolah-olah mereka adalah miliknya.

OLD mempunyai beberapa gejala, antara lain daya tarik luar biasa bagi satu orang, pikiran obsesif tentang orang tersebut, merasakan kebutuhan untuk melindungi orang yang dicintai, pikiran dan tindakan posesif, kecemburuan ekstrem atas interaksi interpersonal lainnya, tingkat percaya diri yang rendah, orang yang menderita OLD mungkin juga tidak bisa menerima penolakan dengan mudah. Dalam beberapa kasus, gejalanya bisa mem- 
buruk di akhir hubungan. Ada tanda-tanda lain dari gangguan ini, seperti teks berulang, email, dan panggilan telepon ke orang yang mereka cintai, kebutuhan untuk terus menerus meminta kepastian, kesulitan menjalin pertemanan atau mempertahankan kontak dengan anggota keluarga karena obsesi terhadap satu orang, memantau tindakan orang yang ia obsesikan, mengendalikan kemana pasangan nya pergi dan kegiatan yang pasangan nya lakukan (Cherney, 2018)

Menurut KBBI (2019), naratif adalah bersifat narasi, bersifat menguraikan (menjelaskan dan sebagainya), prosa yang subjeknya merupakan suatu rangkaian kejadian. Jadi dapat disimpulkan bahwa video musik naratif merupakan video musik yang menceritakan sebuah kisah, secara logis atau berurutan melalui serangkaian peristiwa yang disatukan untuk berjalan sejajar satu sama lain. Kadang-kadang bahkan mungkin tampak seperti film kecil yang dibintangi karakter utama yang seolah-olah berkomunikasi dengan penonton (S, Shubhit, 2014).

Di dalam video musik naratif, audience diajak untuk mengenal bagaimana tahapan dari sebuah hubungan yang tidak sehat, yang bisa

berkembang menjadi cinta obsesif. Video ini tidak bertujuan untuk menyembuhkan penderita OLD, tetapi video ini bertujuan untuk meningkatkan kesadaran para remaja tentang bahaya dari OLD, karena kesadaran merupakan langkah awal menuju kesembuhan.

Hubungan yang tidak sehat biasanya tidak bisa langsung di identifikasi di awal masa pacaran. Semua nya berkembang secara bertahap. Dari rasa cinta berbunga-bunga, lalu berubah menjadi ketergantungan (codependent relationship), lalu jika ketergantungan ini dibiarkan, akan berkembang menjadi cinta obsesif (obsessive love disorder).

Target audiencenya adalah pria dan wanita berusia 18-24 tahun. Format yang digunakan adalah .mp4 dan nantinya akan diunggah ke Youtube. Berupa video musik naratif dengan durasi maksimal 7 menit.

Adapun sinopsis video diawali dengan Aldo terbangun dari tidurnya dengan penuh ketakutan. Ia bermimpi bahwa Kathlyn pergi meninggalkan dirinya demi laki - laki lain. Aldo dan Kathlyn baru berpacaran selama 5 bulan.
Meskipun begitu, Aldo sudah merasa sangat mencintai Kathlyn dan ia tidak mau kehilangan dirinya. Hal ini membuat Aldo menjadi berusaha sebisa mungkin untuk menjaga dan membahagiakan Kathlyn. Namun hal ini juga lah yang ternyata memicu sisi obsesif dari Aldo. Tanpa Aldo sadari, cinta obsesif ini lah yang perlahan merusak hubungan mereka, menjadikan hubungan mereka menjadi tidak sehat karena sangat bergantung dengan satu sama lain.

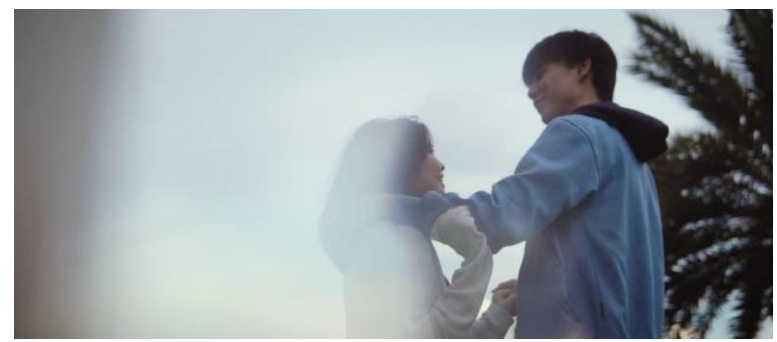

Gambar 1. Falling In Love

\section{Chapter 1 Falling In Love}

Menggambarkan Aldo dan Kathlyn yang sedang jatuh cinta. Menggunakan banyak warna cerah mulai dari setting, kostum, color grading, dan lain-lain.

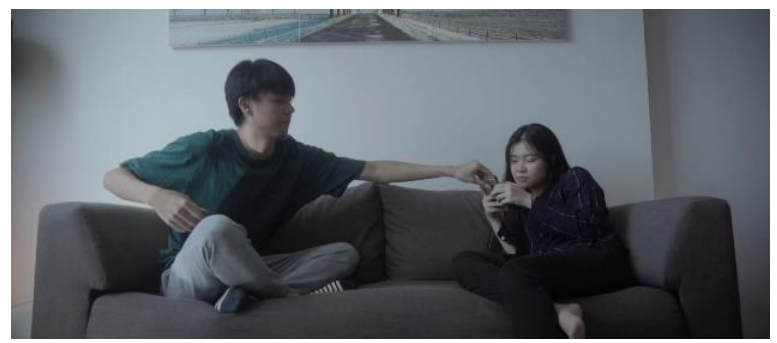

Gambar 2. Codependancy

\section{Chapter 2 Codependancy}

Menggambarkan Aldo dan Kathlyn yang mulai saling bergantung satu sama lain. Menggunakan warna yang lebih gelap dari chapter I dalam pemilihan setting, kostum, color grading, dan lain-lain.

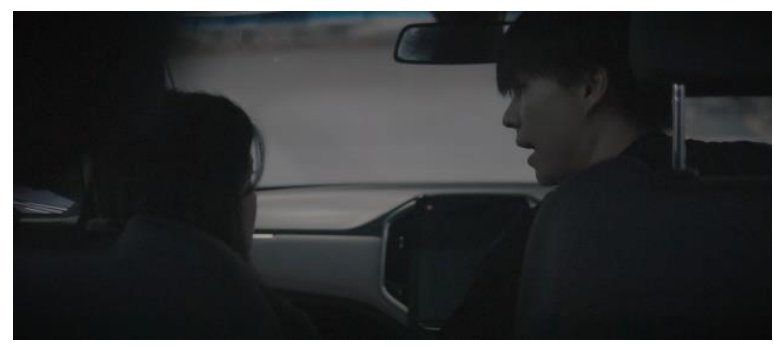

Gambar 3. Obsession

Chapter 3 Obsession

Menggambarkan Aldo dan Kathlyn yang sudah terjebak di dalam sebuah hubungan obsesif. 
Menggunakan warna gelap mulai dari pemilihan setting, kostum, dan color grading yang ada.

Yang diharapkan dari video musik naratif "Stages of Obsessive Love" adalah bagaimana film ini dapat memberi gambaran tentang tahapan dari sebuah hubungan yang berawal dari jatuh cinta lalu menjadi ketergantungan, hingga akhirnya menjadi obsesi. Melihat hal ini, pemakaian warna dalam film mengalami perubahan dari warna cerah (masih penuh kebahagiaan) ke warna gelap (sudah tidak ada kebahagiaan).

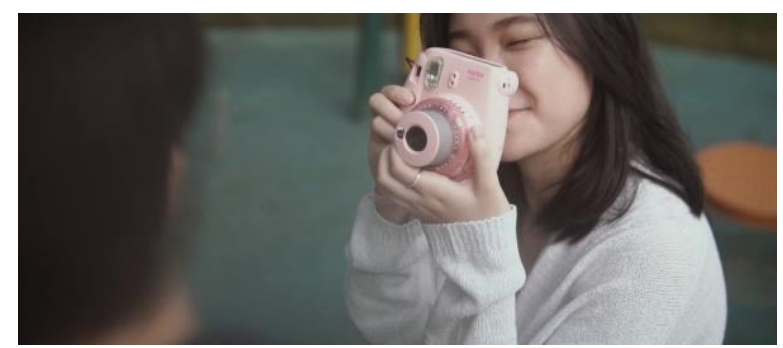

Gambar 4. Scene 1

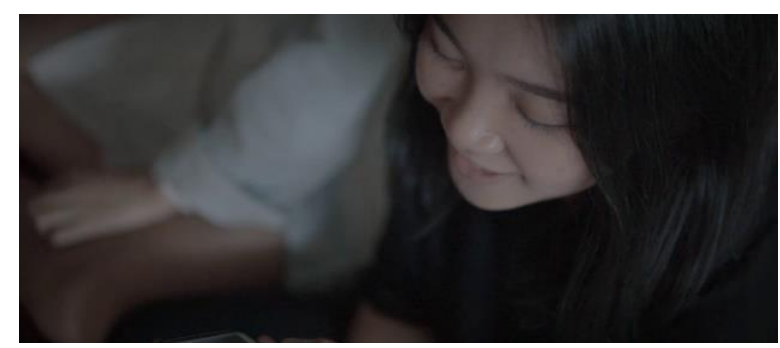

Gambar 5. Scene 2

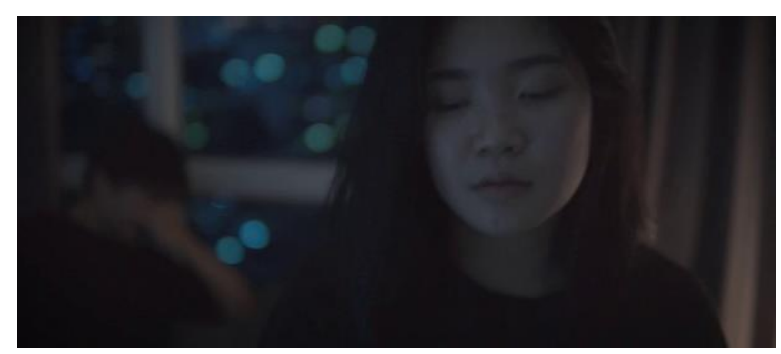

Gambar 6. Scene 3

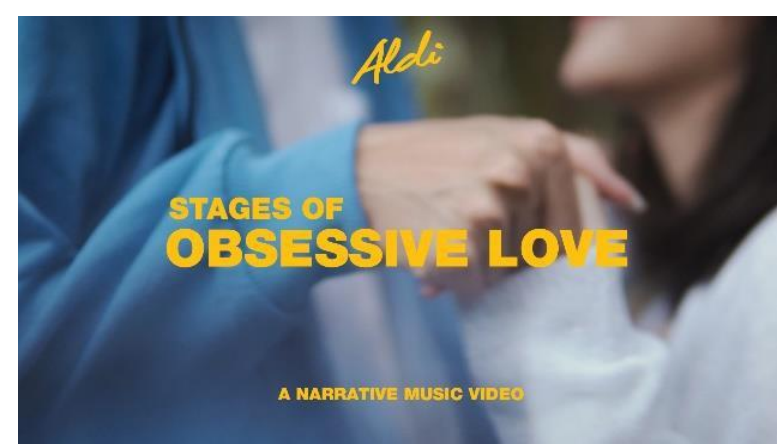

Gambar 7. Thumbnail Youtube

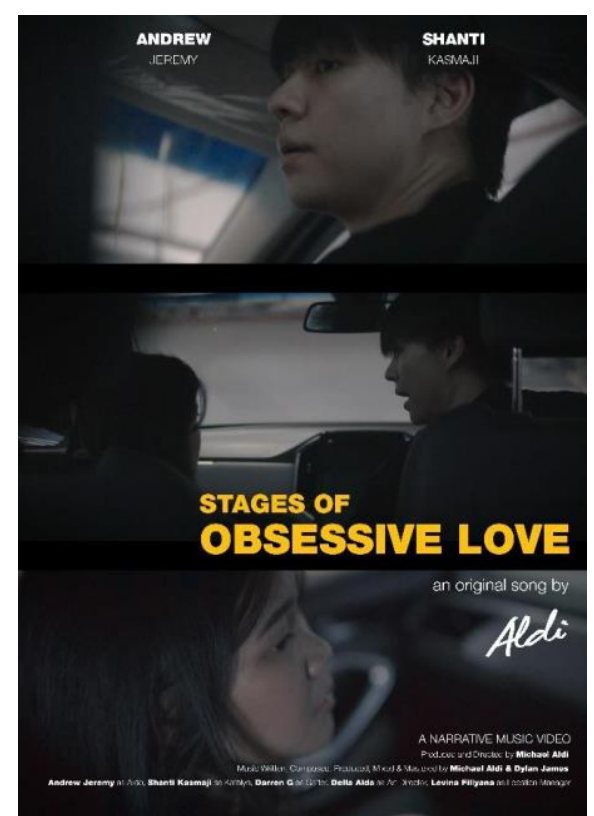

Gambar 8. Poster Video Musik Naratif

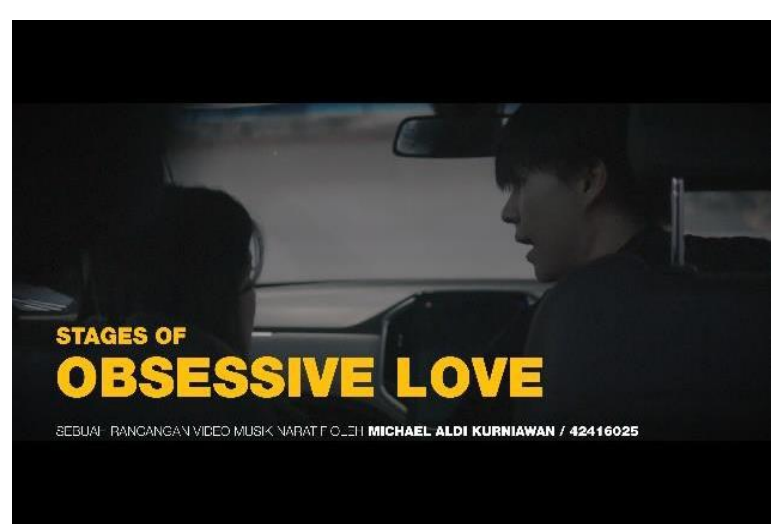

Gambar 9. Cover Production Book

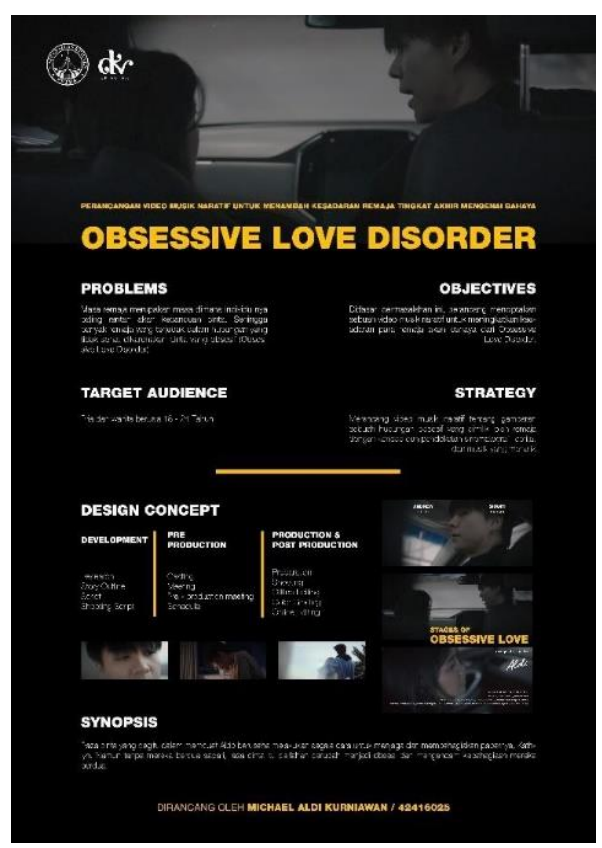

Gambar 10. Poster Konsep 


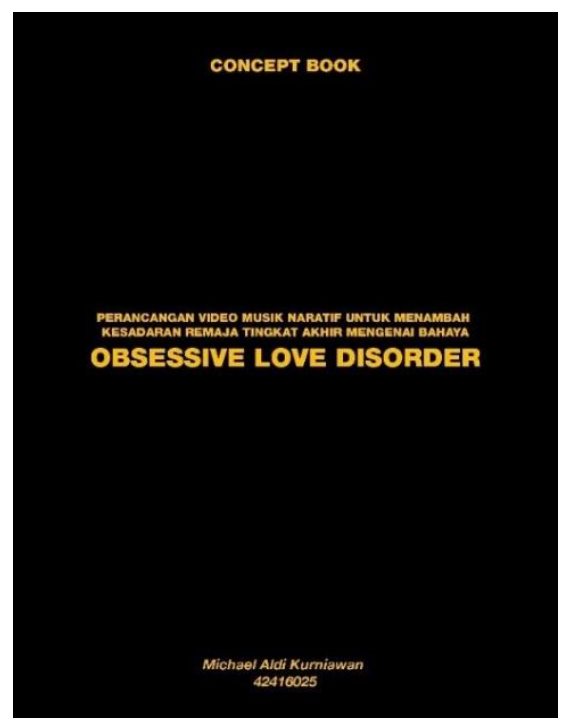

Gambar 11. Cover Buku Konsep

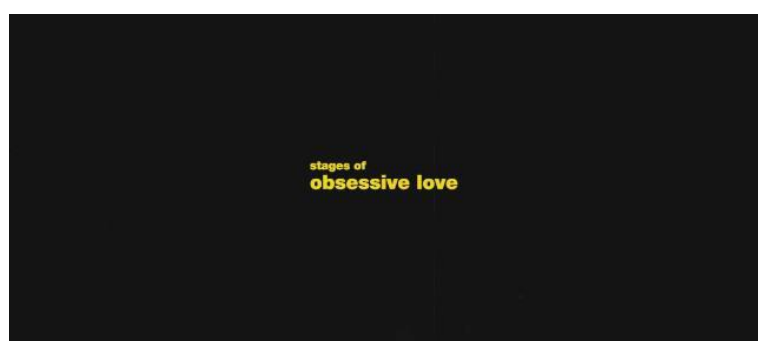

Gambar 12. Teaser $\mathrm{H}-2$

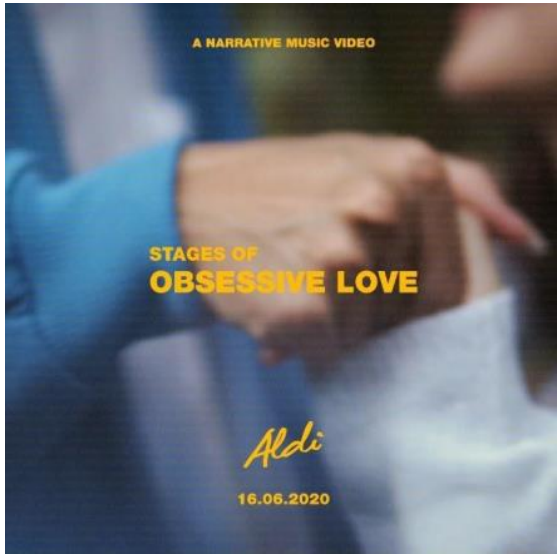

Gambar 13. Teaser $\mathrm{H}-1$

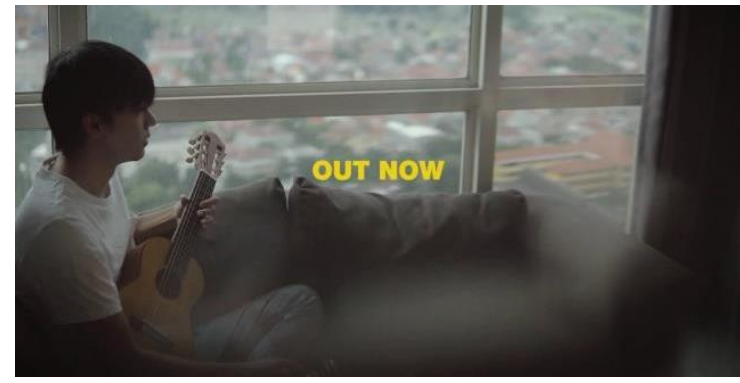

Gambar 14. Teaser Hari - H

\section{Simpulan}

Berdasarkan hasil perancangan video, penulis menyimpul-kan pembuatan video musik naratif tentang bahaya Obsessive Love Disorder ini dilakukan karena banyak remaja yang belum sadar tentang bahaya dari Obesessive Love Disorder, dan bertujuan agar remaja bisa meng-identifikasi dan terhindar dari hubungan obsesif yang berbahaya. Berdasarkan hasil screening pada 15 orang yang termasuk target audience, dapat diketahui bahwa video musik naratif yang dibuat sudah cukup berhasil memberi gambaran seputar bahaya dari Obsessive Love Disorder. Menurut penulis, video musik naratif ini sudah dapat diterima baik dari segi estetis. Dari segi penyampaian pesan perlu lebih banyak menjelaskan tentang latar belakang dari karakter dan juga jalan cerita seharusnya bisa memiliki klimaks yang lebih menarik.

\section{Daftar Pustaka}

Ahmadi, V. 2013, Prevalence of Obsessive Love and Its Association with Attachment Styles, Department of Psychology, Payame Noor University, Ilam, Iran.

Ashar, A. 2019, Kematian Asmaul Husna dan Tingginya Kekerasan dalam Pacaran, Retrieved from: aksaraintimes.id/kematianasmaul-husna-dan-tingginya-kekerasandalam-pacaran/

Cherney, K. 2018, "Obsessive Love Disorder", Retrieved from: htpps://www.healthline.com/health/obsessiv e-love-disorder

Frangklin, R. 2018, Pengaruh Hubungan Toxic terhadap Remaja, Retrieved from: htpps://kompasiana.com/rebeccafrangklin27 27/5dc8f72bd541df4041287e34/pengaruhhubungan-toxic-terhadap-remaja

Kamus Besar Bahasa Indonesia Daring, Retrieved from: https://kbbi.web.id/naratif

S, Shubhit. 2014, How To Make A Narrative Music Video: The Fundamentals, Retrieved from:

https://www.epikmusicvideos.com/blog/72how-to-make-a-narrative-music-video-thefundamentals.html 